\title{
Representações sobre o meio ambiente: da identificação de obstáculos à elaboração de objetivos-obstáculos
}

\author{
Representations about the environment: from obstacles identification to elaboration of objectives-obstacles \\ Salatiel da Rocha Gomes', José Vicente Aguiar de Souza ${ }^{2}$ e lerecê Barbosa ${ }^{3}$ \\ 'Mestrando do Programa de Pós-graduação em Educação e Ensino de Ciências na Amazônia, UEA, Manaus, Am, Brasil \\ 2 Dr. Em Educação, Professor do Programa de Pós- Graduação, UEA, Manaus, Am, Brasil \\ ${ }^{3}$ Dra. Em Educação, Professor do Programa de Pós- Graduação, UEA, Manaus, Am, Brasil
}

\begin{abstract}
Resumo
Este trabalho tem por objetivo identificar as representações que alunos de uma turma do $6^{\circ}$ ano do Ensino Fundamental possuem sobre o meio ambiente e, a partir delas, elaborar objetivos visando suas mudanças e a superação de alguns obstáculos. Fundamentou-se na concepção de obstáculos epistemológicos de Gaston Bachelard e de objetivos-obstáculos de Jean Pierre Astolfi. Caracteriza-se como pesquisa qualitativa, com dados coletados em sete encontros realizados em uma escola pública, utilizando-se como técnicas questionários, observação e visitas a espaços não-formais institucionalizados e não institucionalizados. Os resultados apontam que as representações iniciais dos alunos sobre o meio ambiente voltam-se apenas para o cuidado e amor à natureza, como não jogar lixo e cuidar dos animais. Após a realização dos encontros, notou-se a predominância do pensamento conservacionista, mas com pequenas ampliações sobre a ideia de meio ambiente e suas relações com a sociedade, com destaque para interdependência entre homem e natureza. Destaca-se a importância de atividades centradas na ideia de obstáculos de entendimentos, que por sua vez possibilitam a elaboração de objetivos-obstáculos, ainda que as mudanças conceituais possam ser resistentes e lentas, como mostrou a pesquisa.
\end{abstract}

Palavras-chaves: Meio ambiente. Representações. Obstáculos. Objetivos-obstáculos

\begin{abstract}
This work aims to identify the representations that students in a class of 6th grade of elementary school have on the environment and, from them, draw your changes and goals aimed to overcome some obstacles. Was based on the concept of epistemological obstacles of Gaston Bachelard and goals from Jean-Pierre Astolfi obstacles. Is characterized as qualitative research, with data collected in seven meetings in a public school, using techniques such as questionnaires, observation and visits to non-institutionalized and non-institutionalized formal spaces. The results indicate that the initial representations of students about the environment turn only for the care and love of nature, as not littering and taking care of animals. After conducting the meetings, it was noted the predominance of conservationist thought, but with small expansions on the idea of the environment and its relations with society, with emphasis on the interdependence between man and nature. Highlights the importance of activities centered on the idea of understanding obstacles, which in turn enables the development of goals, obstacles, although the conceptual changes can be tough and slow, the survey showed.
\end{abstract}

Keywords: Environment. Representations. Obstacles. Goals- obstacles 


\section{INTRODUÇÃO}

As inúmeras pesquisas sobre as representações dos alunos fornecem dados importantes para se pensar o desenvolvimento do ensino-aprendizagem no contexto escolar, principalmente no ensino de ciências. Elas podem orientar a prática pedagógica como apontam os estudiosos desta questão. Necessita-se conhecê-las para a elaboração de objetivos e sequências didáticas que possibilitarão novas representações e aquisição de um novo saber.

Nesta linha teórica que busca aproximar didática e epistemologia, pretende-se analisar as representações que os alunos possuem sobre o meio ambiente, à luz da epistemologia de Gaston Bachelard, os obstáculos epistemológicos e quais os tipos de objetivos-obstáculos podem ser traçados para superar tais obstáculos. Nortearam esse estudo as seguintes questões: O que são e quais os tipos de obstáculos epistemológicos representados pelos estudantes? Quais as representações sobre meio ambiente que os alunos possuem e que tipo de obstáculos podem ser identificados? Uma sequência didática a partir de objetivos -obstáculos pode contribuir para a mudança de conceitos quando o tema é meio ambiente?

As reflexões teóricas serão realizadas a partir dos textos de Bachelard (1996), Astolfi, Peterfalvi e Vérin (1998), Pozo e Crespo (2002 e Carvalho (2008). Trata-se de uma pesquisa de campo, de abordagem qualitativa, utilizando-se como técnicas de coletas de dados questionários com perguntas abertas, observação e visitas a espaços não-formais institucionalizados e não institucionalizados. Participaram desse estudo 30 alunos do $6^{\circ}$ ano de uma escola municipal da zona leste da cidade de Manaus.

\section{OS OBSTÁCULOS EPISTEMOLÓGICOS E AS REPRESENTAÇÕES: QUANDO O ALU- NO TEM DIFICULDADES E A ESCOLA TAMBÉM}

Quando se procuram as condições psicológicas do progresso da ciência, logo se chega à conclusão que é em termos de obstáculos que o problema do conhecimento científico precisa ser apresentado (BACHELARD, 1996, p.17). Essa definição remete-nos a pensar não somente sobre a evolução do pensamento histórico sobre a ciência, mas em analisarmos o contexto educacional, principalmente as manifestações de aprendizagem dos alunos. Acredita-se que é necessário partir daquilo que os alunos já conhecem ou das suas experiências, uma vez que não se pode considerar o aluno como sujeito vazio. Parte-se, portanto, da necessidade de conhecer suas representações sobre as temáticas estudadas.

Uma representação, no plano didático, corresponde a um modelo pessoal de organização dos conhecimentos, relativamente a um plano específico. Para que ocorra a passagem de tais representações a uma esfera maior de aprendizagem, como do conhecimento científico, é preciso reorganizar os processos cognitivos, que requer uma forma de avaliação diagnóstica inicial (ASTOLFI et all, 1997).

A representação é, em primeiro lugar, uma tarefa intelectual do aluno, cujas características dependem, certamente, de uma organização cognitiva em memória (...) em cada sequência didática nova, o aluno mobiliza, a partir do seu fundo próprio, o que lhe parece adaptado àquilo que pensa que se espera dele; as representações são antes consideradas como estratégias cognitivas, as únicas de que o aluno dispõe e sobre as quais deveria apoiar uma pedagogia diferenciada, para facilitar a sua evolução positiva (ASTOLFI et all, 1997)

Bachelard (1996) considera que obstáculos epistemológicos são entraves que fazem com que o aluno tenha dificuldades em deixar o conhecimento comum e se aproximar do conhecimento científico. O autor aponta os seguintes obstáculos: a experiência primeira, o conhecimento geral, obstáculo verbal, conhecimento unitário e pragmático, substancialismo, realismo e o animismo. Para ele, "o ato de conhecer dá-se contra um conhecimento anterior, destruindo conhecimentos mal estabelecidos, superando o que, no próprio espírito, é obstáculo à espiritualização" (Bachelard, 1996, p.17). Nesse sentido, cabe ao professor ajudar o aluno a romper com o conformismo do conhecimento anterior a fim de formar o espírito científico. Porém, essa forma de atuação docente não é automática, tampouco fácil de ser realizada nas salas de aulas, principalmente quando se reúne uma série de dificuldades que subjazem na escola, desde a formação de professores às condições de trabalho. Dada a brevidade e recorte do texto, não é intenção aprofundar essas questões, todavia, é importante que reflitamos sobre os efeitos dos obstáculos pedagógicos para a aprendizagem dos alunos.

É comum, em sua maioria, que a escola tenha como objetivo maior o cumprimento do cur- 
rículo mínimo ou da proposta pedagógica de cada secretaria de ensino. Contudo, para início de um planejamento docente razoável e coerente, o professor necessitaria iniciar a partir das representações alunos, daquilo que eles já conhecem. Geralmente não é isso que acontece; parte-se da intenção geral, dos objetivos curriculares e das pretensões duvidosas de um currículo, por vezes, surreal, ultrapassado e de conteúdos priorizados (Pozo e Crespo, 2002). Com isso, as dificuldades conceituais dos alunos permanecem, pois ao invés de serem elaborados planos vinculados aos obstáculos subjacentes do aluno, prioriza-se um ensino voltado ao cumprimento de metas, por vezes, oleado de intenções políticas. A lógica deveria ser diferente; ao invés de um olhar voltado ao ensino, necessitaríamos iniciar pela aprendizagem. Nas palavras de Vasconcelos, "a existência de um programa a ser cumprido, custe o custar, torna a relação pedagógica artificial, na medida em que os objetivos estão dados previamente independentemente da realidade de aprendizagem dos alunos $(2014$, p.8).

A título de exemplo, algumas salas de aula são formadas a partir de um objetivo escolar: equilibrar o rendimento acadêmico entre as turmas. Mesmo sabendo-se do nível de aprendizagem real dos alunos, permanece uma visão voltada a resultados, uma vez que é difícil justificar o porquê de uma turma com tantos alunos possuírem a "nota" abaixo do esperado. Se a escola tivesse como prioridade a superação das fragilidades, isso seria uma estratégia pedagógica coerente e mais presente, pois possibilitaria ao professor partir de um nível razoavelmente comum. Então, haveria a possibilidade de planejar uma sequência didática exequível, com materiais potencialmente significativos destinados àqueles alunos com diferentes ritmos de aprendizagem, o que possivelmente superaria alguns obstáculos (ASTOLFI, PETERFALVI e VÉRIN, 1998). Por isso, salienta-se o desafio da escola no contexto atual, pois nesse tempo o acesso à informação é instantâneo e volumoso. Mas, como a escola pode ser interessante ao aluno e sendo capaz de transformar essas informações em conhecimentos?

Não é um objetivo simples face aos contextos, processos e até mesmo relações. Dizemos isso pelas dificuldades em lidar com diferentes alunos, pais e comunidade em um tempo em que a escola já não é a única via de acesso à informação e conhecimento. Para os alunos, ela tornou-se desinteressante e por vezes entediante. Parece improdutiva na sua própria produtividade (FRIGOTO, 2006).

Acontece que encontramos novos discursos para antigos problemas. Diante da pergunta básica do porquê de tanto alunos ficarem reprovados devido não saberem ler, há professores que patologizam o aluno: ele tem dislexia, dislalia e tantas outras síndromes, fazendo-nos pensar em outro chavão que está em moda: a medicalicalização do ensino. É mais justificável e bem aceito dizer que os alunos têm dificuldades e encaminhá-los para outros profissionais que darão "um jeito" nos problemas que se tornaram entraves e gargalos à aprendizagem dos estudantes. "Para que o processo de mudança possa avançar, antes de criticar a reprovação em si, temos de desconstruir a culpabilização do aluno (VASCONCELOS, 2014, p.10), entendendo nessa relação que "o fracasso escolar é bem mais do que um simples acidente de percurso, é o fracasso de toda a pessoa, um fracasso social, um fracasso educativo para as famílias e um fracasso subjetivo para os alunos" (DUBET, 2008, p.52).

Nessa ponte de análise, entende-se que a escola democraticamente necessita possibilitar a aprendizagem para todos. Para que isso aconteça, necessita-se retirar velhos estereótipos geralmente vinculados aos alunos. A família, o sistema escolar, o Estado, o aluno e a comunidade possuem suas funções para o êxito na vida dos estudantes, todavia, a escola e o professor também possuem suas tarefas, talvez até mais significativas; quando não as cumpre, decerto haverá obstáculos para a aprendizagem (VASCONCELOS, 2014).

É necessário que a didática do professor não seja uma retórica vazia e que a comunicação na sala de aula não se torne uma armadilha para a aprendizagem; deve-se retificar representações, por vezes tributárias, e que em certa medida não ajudam na construção de conhecimentos e também nas suas ressignificações. Precisa-se criar condições de reflexões das ações docentes que envolvam os alunos que não conseguem compreender novos conceitos nem adquirir habilidades que o fariam aprender a aprender (ASTOLFI, PETERFALVI e VÉRIN, 1998). Daí a necessidade de uma leitura sobre alguns aspectos do ensino.

\subsection{Aspectos para se pensar o ensino}

Resgatamos dos textos de Astofi, Peterfalvi e Vérin(1998) algumas reflexões importantes para pensarmos o ensino:

- $\quad$ É importante manter os conteúdos implícitos. Quando isso acontece, o aluno necessitará 
buscar respostas, pesquisar, relacionar e confrontar situações e variáveis; com isso, constantemente, o professor propiciará um processo de devolução, onde o principal objetivo consiste em estimular os alunos em resolverem o problema, ou pelo menos, que o problematizem ainda mais;

- $\quad$ Ressalta-se que, em determinadas situações, alguns obstáculos, aparentemente ultrapassados, reaparecerão. Nesse caso, existirá uma regressão positiva, podendo o professor ressignificar aquele conhecimento obliterado (Ausubel, 1980);

- $\quad$ Considera-se primordial a superação da estrutura monológica no ensino. O que ocorre é que se muda a forma (dialogal), mas não muda a estrutura pois geralmente há a participação dos alunos, mas não debates.

- $\quad$ Sugerem-se práticas docentes baseadas em sequências didáticas com vistas a características mediadoras (estímulo à participação e condutas ativas com criações de situações - problemas) e adaptadoras (orientação e acompanhamento, reconhecendo que os alunos possuem suas próprias representações). Com isto, evita-se a monotonia repetitiva dos hábitos didáticos e profissionaliza-se mais o trabalho docente;

Considerando a concepção de Piaget onde o processo de desenvolvimento cognitivo não acontece aleatoriamente tampouco bruscamente, é preciso pensar o ensino visando formas de aprendizagens que possibilitem não somente as mudanças cognitivas, como também conceituais. Uma sugestão é o trabalho a partir de objetivos-obstáculos.

\subsection{Os objetivos- obstáculos como proposta didática}

A expressão objetivos-obstáculos, formulada por Martinand, reconhece a importância de uma proposta pedagógica coerente e relacionada à situação atual de aprendizagem dos alunos, pois "eles que devem ser colocados no centro quando se definem os verdadeiros objetivos" (ASTOLFI, PETERFALVI e VÉRIN, 1998, p.65). Acredita-se que é na intenção de superar os obstáculos referentes aos conceitos iniciais, que se traça a ideia de objetivos, uma estratégia que visa o rompimento e ajuste das estruturas conceituais prévias e ainda conflituosas. Fazendo uma ponte com o conceito de concepções alternativas, considera-se que:

As concepções alternativas, como todo conhecimento primeiro, ainda que sejam ideias que se precipitam do real, ainda que espontâneas e erradas, são condições necessárias ao desenvolvimento cognitivo e à aquisição do saber racional. A verdade resulta de uma rejeição sucessiva de erros como caminho na construção do conhecimento (SANTOS, 1991, p.130).

A proposta didática de aprendizagem construída com base nos objetivos-obstáculos, estimula o aluno conscientiza-se de seu próprio funcionamento intelectual, reconhecendo alguns obstáculos e a necessidade de superá-los. A fissuração desse obstáculo acontece na medida que o aluno desestabiliza-se, através de um conflito sócio-cognitivo, mas a superação desse obstáculo somente se dará na medida que for disponibilizado um modelo explicativo alternativo proporcionando, possivelmente, a sua automatização de forma que consiga utilizar em outros contextos (ASTOLFI, PETERFALVI e VÉRIN, 1998).

O trabalho de campo teve como eixo as reflexões sobre o meio ambiente, voltando-se à ideia de se trabalhar com as representações dos alunos e com os objetivos-obstáculos. Com isso, é importante elencarmos algumas leituras sobre o meio ambiente, de modo a reconhecê-las a partir de diferentes estilos de pensamento, conforme a linguagem Fleckiana (FLECK, 2010).

\subsection{Meio Ambiente: Características, compreensões e algumas leituras}

A questão ambiental, com toda a sua complexidade tornou-se um dos temas bastante discutidos no cenário educacional. As pesquisas apontam para um predomínio de pensamento conservacionista, naturalista, ecologista. A atenção tem se concentrado em relacionar o meio ambiente aos aspectos biológicos, sem considerar as outras dimensões.

Nos PCN's, meio ambiente é definido como um espaço em que um ser vive e se desenvolve, trocando energia e interagindo com ele, sendo transformado e transformando-o (BRASIL, 1997). Nesse sentido, se o meio ambiente é também um espaço de transformação e de convivência, devemos considerar, portanto, os elementos naturais e físicos e os aspectos socioculturais encontrados nas áreas urbanas e rurais. Os elementos naturais podem ser definidos da seguinte maneira:

Aqueles elementos que são "como a natureza os fez", sem a intervenção direta do homem: 
desde cada recurso natural presente num sistema, até conjuntos de plantas e animais nativos, silvestres; paisagens mantidas quase sem nenhuma intervenção humana; nascentes, rios e lagos não atingidos pela ação humana (BRASIL, 1997, p.32).

Outra característica corresponde aos espaços já modificados pelo homem, como praças, jardins, plantações, praias urbanizadas, bosques, áreas de lazer, dentre outros, que são ambientes criados para convivência. Esses espaços, ainda pouco inseridos como integrantes do meio ambiente, necessitam de ações principalmente do Estado para que se efetivem ou se mantenham. Por isso, a importância de uma discussão que não esgote o meio ambiente apenas em um pensamento naturalista, mas que consiga dialogar com outras dimensões, como política, econômica e a social. Deve-se orientar por uma racionalidade complexa e interdisciplinar, em que as interações entre a cultura, sociedade e base física devem estabelecer uma relação dinâmica e mútua (CARVALHO, 2008).

Percebe-se que é natural nas escolas não falar muito dessas dimensões, seja por sua complexidade ou pela própria formação dos professores. Todavia, essas discussões necessitam ser postas à escola, para que se consiga formar alunos que não reduzam o conceito de meio ambiente a uma simples ação humana, realizada em seu cotidiano. A citação apresentada abaixo compreende essas relações da seguinte maneira:

Deve-se considerar que, como a realidade funciona de um modo sistêmico em que todos os fatores interagem, o ambiente humano deve ser compreendido em todos os seus inúmeros problemas. Tratar a questão ambiental, portanto, abrange toda a complexidade da ação humana: se quanto às disciplinas do conhecimento ela é um tema transversal, interdisciplinar, nos setores de atuação da esfera pública ela só é consolidada numa atuação do sistema como um todo, sendo afetada e afetando todos os setores: educação, saúde, saneamento, transporte, obras, alimentação, agricultura, etc (BRASIL, 1997, p.44).

$\mathrm{O}$ argumento acima vem dos PCN's, que é um documento norteador a prática pedagógica dos professores. Mas, por inúmeros fatores, a escola tem dificuldades em trabalhar nessa perspectiva crítica e que vá além de uma lente predominantemente naturalista. Nessa proposição, ressalta-se o alerta do risco de reduzir o ato educativo à transmissão de informações das ciências naturais, onde o professor teria a função de minimamente difundir as verdades, da forma como se constituíram, o que o transforma em um decodificador e difusor dessas informações prontas e acabadas (CARVALHO,2008).

\section{PERCURSO METODOLÓGICO DA PESQUISA}

A pesquisa realizou-se durante os meses de outubro e novembro de 2014 em uma escola municipal da zona leste da cidade de Manaus, com a participação de 30 alunos do $6^{\circ}$ ano no turno vespertino. A escola atualmente trabalha em três turnos e possui 915 alunos, nos níveis de ensino fundamental dos anos iniciais e finais, além da modalidade de $1^{\circ}$ e $2^{\circ}$ segmento da EJA.

Reitero que se trata de uma pesquisa de campo, de abordagem qualitativa e que se utilizou de observações, rodadas de conversas, aplicações de questionário com perguntas abertas e visitas a espaços não-formais institucionalizados e não institucionalizados como técnicas para coletas dos dados. Foram realizados 7(sete) encontros:

- $\quad 1^{\circ}$ Encontro: Foi aplicado um questionário com apenas uma pergunta aberta que visava verificar as representações iniciais dos alunos sobre o meio ambiente através de um texto escrito e desenho. Teve-se o cuidado para que os alunos ficassem livres para se posicionarem sem qualquer tipo de indução das respostas, tanto pelo professor da turma quanto pelo pesquisador. Elaboramos a seguinte questão: Escreva um texto sobre sua compreensão a respeito do tema Meio Ambiente.

$2^{\circ}$ Encontro: Ocorreu na própria sala de aula através de uma rodada de conversas. Foi o momento de ouvi-los a respeito de suas produções textuais e desenhos.

- $\quad 3^{\circ}$ Encontro: Reflexões junto com os alunos a respeito de algumas leituras sobre ambiente e sociedade.

- $\quad 4^{\circ}$ Encontro: Conversas com os alunos na área verde da escola, com vistas ao Lago do Aleixo. A ideia foi de problematizar questões que envolvessem os ciclos da natureza, sociedade e conservação e preservação ambiental;

- $\quad 5^{\circ}$ Encontro: Aula-passeio nos entornos da escola seguindo as orientações propostas pela técnica desenvolvida por Celestin Freinet (1975). Visitou-se alguns espaços de convivência, como: 
praças, proximidades do lago do Aleixo e um Campo de Futebol;

- $\quad 6^{\circ}$ encontro: Visita ao Bosque da Ciência - INPA, um espaço não-formal institucionalizado;

$7^{\circ}$ Encontro: Aplicação de questionário com uma pergunta aberta, a mesma utilizada no $1^{\circ}$ encontro, a fim de verificar se houve novas representações sobre o meio ambiente.

\section{REPRESENTAÇÕES SOBRE O MEIO AMBIENTE: IDENTIFICAÇÃO DE ALGUNS OBS- TÁCULOS}

O objetivo de verificar as representações iniciais dos alunos consistiu em compreender como eles percebem o meio ambiente e a partir dessas percepções, montar objetivos e sequências didáticas que visem mudanças conceituais. Em uma linguagem ausubeliana, partindo-se dos conhecimentos prévios e utilizando-se de materiais potencialmente significativos.

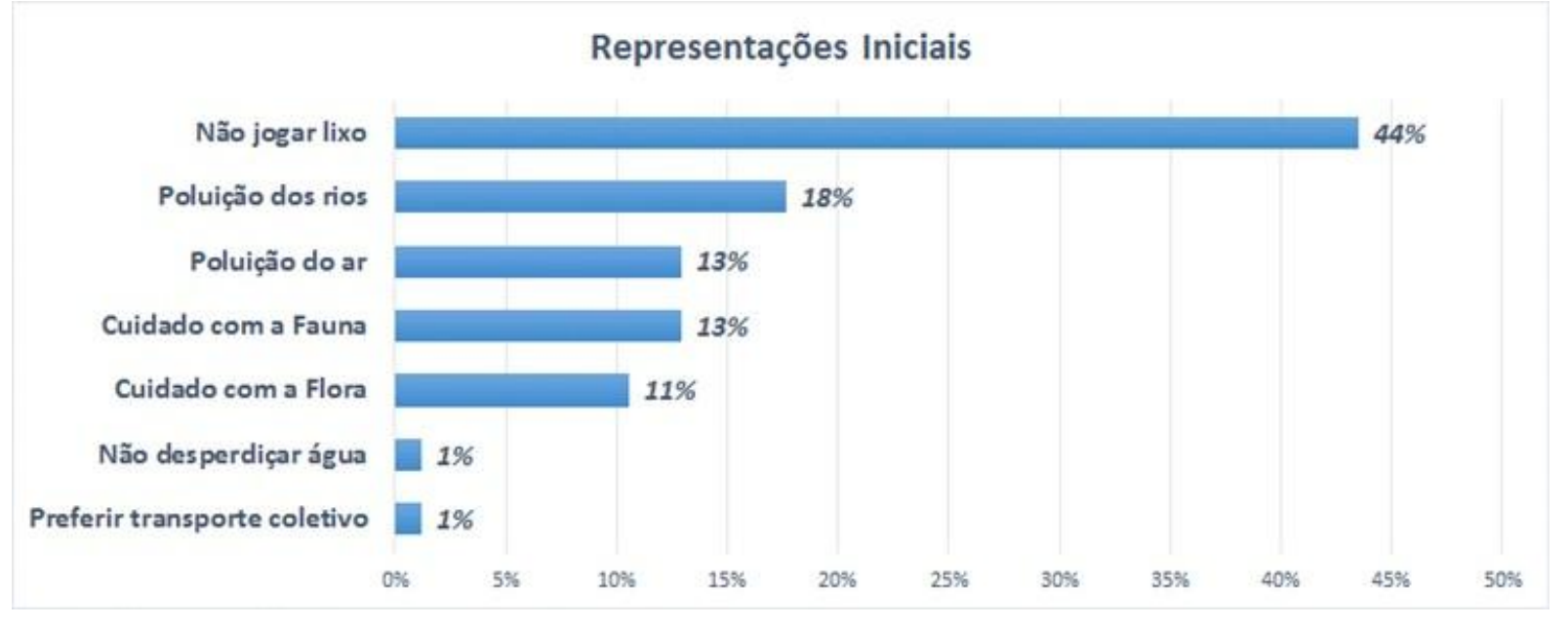

Gráfico 1 - Representações iniciais sobre meio ambiente

Fonte: Dados da Pesquisa

Percebe-se que a maior representação de meio ambiente para os alunos consiste no cuidado em não jogar lixo na rua. Em sua maioria, destacam que o lixo deve ser apenas direcionado para o local apropriado, ou seja, na lixeira. Os alunos não conseguem perceber temáticas implícitas e que envolvem leituras sobre a sociedade, como o consumo, desperdícios e aproveitamento do lixo por catadores, que seria uma discussão sobre aspectos da sociedade. É importante considerar que a discussão sobre o lixo ocorre destacando seu recolhimento e não sua produção, principalmente relacionando-o ao nosso consumo intenso.

Essas representações destacam a tendência conservacionista da Educação Ambiental, onde há uma visão incompleta do meio ambiente. Foca-se a natureza e as ações antrópicas, desprovidas de análises que relacionam aos diversos aspectos: políticos, sociais, culturais e econômicos. Quando não há um entrelaçamento dessas relações, a Educação Ambiental torna-se ingênua e acrítica, o que possibilita a permanência de uma visão apenas conservacionista e romântica.

As concepções ainda sincréticas:

"O meio ambiente faz parte do lixo, da poeira e da sujeira. Jogar as coisas no lixo e não jogar no rio senão fica com cheiro ruim. O carro do lixo faz parte do meio ambiente" (Aluno M).

"O meio ambiente é uma cultura para salvar o ecossistema, mas também são os outros realmente que não têm que jogar lixo na lixeira, materiais recicláveis na ordem da lixeira, tem que jogar lixo na lixeira, mas tem que jogar lixo no lixo e não tem que jogar lixo nas ruas" (Aluno Y).

Os desenhos, da maioria dos alunos, apontam a mesma representação escrita por eles em relação ao meio ambiente, que corresponde a necessidade de não jogar lixo no chão e que o homem é o responsável pelas degradações ambientais. 


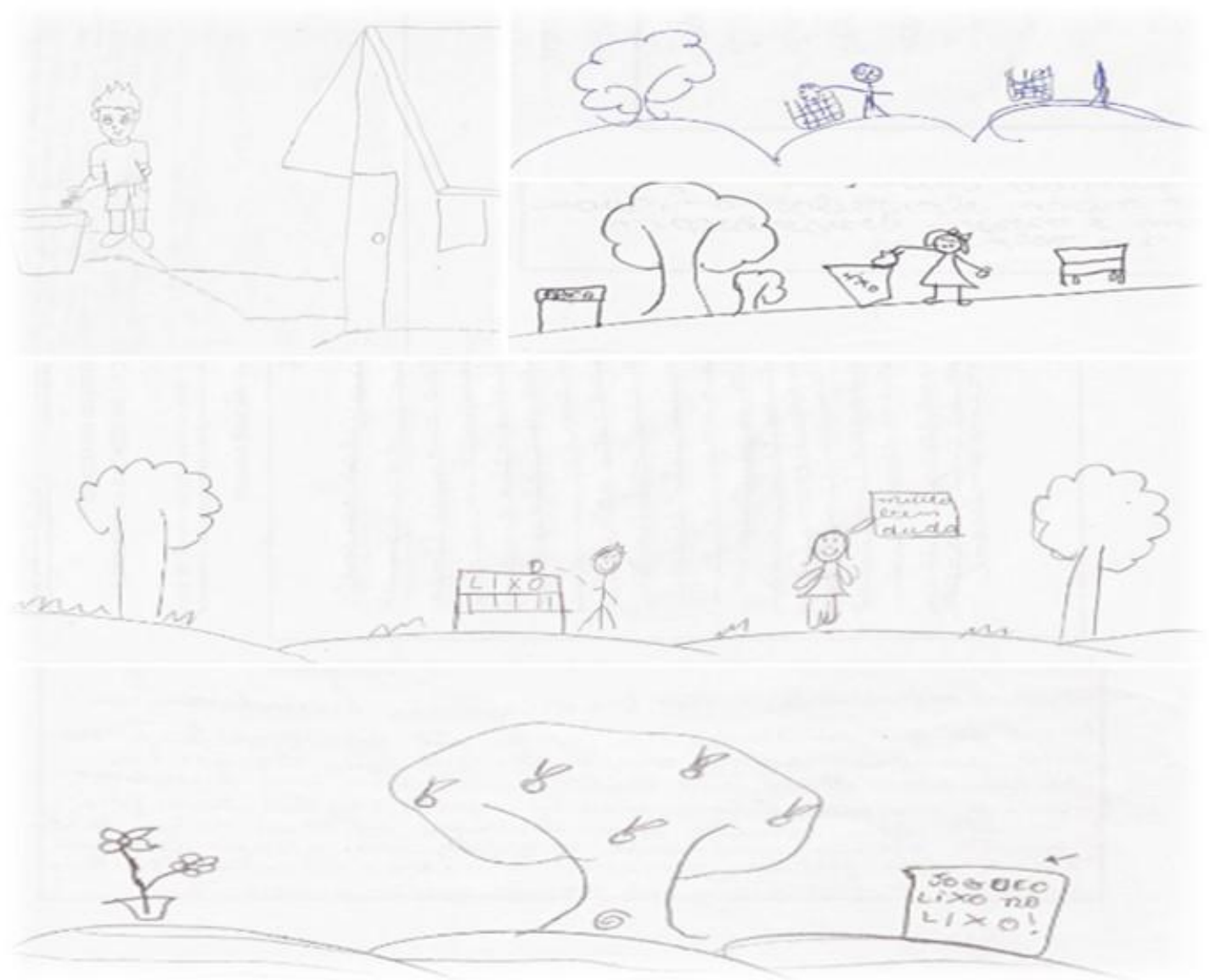

Figura 1 - Representações iniciais sobre meio ambiente Fonte: Dados da Pesquisa

Os desenhos que as crianças fazem sobre o meio ambiente geralmente é uma reprodução de como são apresentados pelo livro didático ou como o professor faz em sala de aula. Por isso, a ideia de uma árvore com traços sempre em forma de uma copa e a representação das pessoas jogando lixo no lixo, sem quaisquer análises de como foi produzido, simplificando, por vezes, a educação ambiental às boas práticas de coleta seletiva. Acredita-se que essa visão incompleta e fragmentada são frutos de obstáculos verbalistas, onde uma única palavra ou imagem constitui todo o entendimento de um tema e de um obstáculo decorrente do conhecimento geral (Bachelard,1996).

\section{A ELABORAÇÃO DOS OBJETIVOS -OBSTÁCULOS}

Caracterizou-se nas representações dos alunos a ideia de meio ambiente como apenas a natureza e a ações da agressão do homem sobre. Diante desta situação traçou-se objetivos que possibilitassem momentos de debates e experiências práticas que possibilitassem ressignificações e possíveis mudanças conceituais sobre o tema. Com isso, montou-se a sequência didática:

$1^{\circ}$ Objetivo: Utilizar textos e esquemas, onde os alunos possam identificar as intervenções com as quais a sociedade, local, nacional ou global, vem realizando e que tipo de problemas isso gera ao meio ambiente.

$2^{\circ}$ Objetivo: Desenvolver na sala de aula, um diálogo considerando os conteúdos: a interdependência homem e natureza, saneamento básico, industrialização, a criação de "lixões" como fonte 
de renda para muitas famílias, biodiversidade, pobreza. Esses enfoques possibilitarão, mesmo que incompleto ainda, um olhar sobre o princípio apontado na Conferência Intergovernamental de Educação Ambiental de Tbilisi: Considerar o meio ambiente em sua totalidade: em seus aspectos natural e construído, tecnológicos e sociais (econômico, político, histórico, cultural, técnico, moral e estético).

$3^{\circ}$ Objetivo: Utilizar a área interna da escola - jardim e área verde - como espaços de reflexão sobre os temas discutidos na sala de aula.

$4^{\circ}$ Objetivo: Realizar excursão com os alunos nos entornos da escola e em um espaço nãoformal institucionalizado, cuja finalidade consiste em relacionar o meio ambiente em seus diferentes aspectos, verificado a partir dos espaços de convivência as suas relações. Trata-se de uma atividade onde os alunos irão anotar suas principais impressões.

$5^{\circ}$ Objetivo: Refazer com os alunos o mesmo questionário adotado para reconhecimento das suas representações iniciais, para que se possa analisar as mudanças conceituais.

\section{6 À VISTA DO LAGO DO ALEIXO: REFLEXÕES SOBRE MEIO AMBIENTE E SOCIEDA- DE}

Curiosos e motivados para uma "aula diferente" nos entornos da escola, os alunos comentavam entre si que já sabiam o que tinha lá fora, inclusive que já haviam "fugido" da escola por aqueles espaços que percorreriam. Nos fundos da escola, existe uma área verde grande, com diferentes tipos de árvores, mas quase não explorada nas práticas pedagógicas conforme relato da pedagoga. A primeira parada chamou logo a atenção dos alunos. Visualizaram um homem dormindo embaixo de uma árvore e assustados, perguntaram-se: Ele está morto? O que ele está fazendo aí? Discutimos, então, algumas relações sociais presentes na sociedade como moradia, pobreza e cidadania. Ao discutir-se sobre esses aspectos, ainda mantinham seus olhos fitados no homem, seja por medo ou curiosidade. Ressalta-se a potencialidade deste entorno do colégio para o ensino de ciências. Inúmeras árvores são encontradas nesses espaços, como as que produzem goiaba, abacate, tucumã, taperebá, ingá, manga, dentre outras plantas, matos e animais. Como atividade pedagógicas poderiam ser confeccionadas estações que possibilitariam o conhecimento biológico das espécies de árvores, como também realizar momentos de observação, onde os alunos perceberiam as relações de interdependências entre os elementos bióticos e abióticos da natureza.

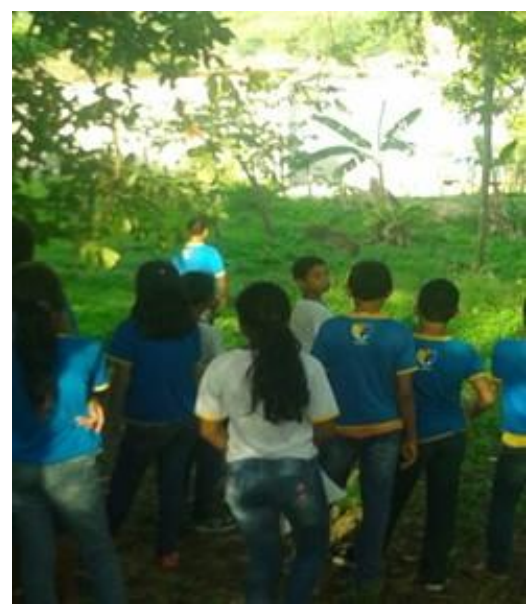

Figura 2 - Visita no lago do Aleixo

Fonte: Dados da Pesquisa

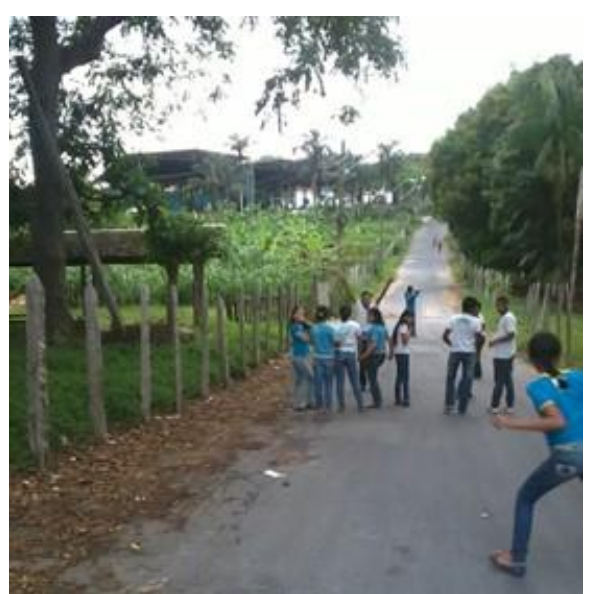

Figura 3 - Caminhada no entorno da escola Fonte: Dados da Pesquisa

Após esse momento, os olhares voltaram-se ao lago do Aleixo, e por sorte, encontramos canoeiros que treinavam e catraias que faziam transportes de pessoas. Os alunos comentavam que o meio ambiente pode gerar momentos de lazer e de renda também. A partir dessa fala, analisamos os espaços de lazer que existem no bairro, possibilitando a eles a ideia de que esses espaços devem ser propor- 
cionados à comunidade pelo Estado, o que corresponde a interpelação entre sociedade e natureza.

A natureza é apresentada como tendo relação direta como o meio ambiente; admiravam-se quando encontravam lixos, pássaros ou algo diferente como o ataque de formigas. Um dos alunos comentou que as formigas atacam quanto a atacamos também, por isso elas se defendem. Mesmos com algumas reflexões na sala de aula sobre essa relação com a sociedade, os alunos mantinham-se a sua ideia principal de que é necessário amar a natureza e cuidar dela, mas que já conseguiam estabelecer uma relação razoável com a sociedade.

"Eu entendi que natureza é também onde nós convivemos, de dia e de noite. Ver os pássaros, as árvores, as frutas e muito mais e também que as pessoas precisam da natureza para sobreviver" (Aluno C).

"Por que nós temos que cuidar? Porque o meio ambiente é vida, sem as árvores todos nós poderíamos morrer, por isso ele é importante para nós, humanos, e para os pássaros" (Aluno L).

"Consegui ver o meio ambiente de outro olhar; eu já vi aquelas imagens várias vezes, mas hoje eu consegui ver, refletir, pensar o meio ambiente e a biodiversidade, tudo o que tem na vida, do rio grande do Aleixo até as formiguinhas, acho que nós temos que preservar não porque nos dá benefícios, mas porque está ligada com a gente" (Aluno D).

"O meio ambiente não é só árvores, pássaros, água, lixo, mas sim os homens, fábricas. Muita gente não tem o que comer, passa fome todos os dias, vão atrás de lixo ver se tem restos de comidas para se alimentar; a maioria não tem casa para morar e os governadores não estão nem aí pra eles, só querem saber de ganhar dinheiro (...) inventaram uma fórmula das frutas crescerem mais rápido e isso não se deve fazer porque a natureza tem o seu jeito de crescer, tem o seu tempo próprio de se reproduzir" (Aluno M).

Percebe-se que, apesar das ideias ainda fragmentadas, os alunos já começam constituir um olhar que não se esgota em apenas preservar ou cuidar da natureza, mas de interdependência, o homem também necessita para sobreviver, por isso, cuida dela também.

Trata-se aqui de construir uma cultura ecológica que compreenda natureza e sociedade com dimensões intrinsecamente relacionadas e que não podem mais ser pensadas - seja nas decisões governamentais, seja nas ações da sociedade civil - de forma separada, independente ou autônoma (CARVALHO, 2008, p.141).

Com as rodadas de conversas e as visitas ao entorno da escola, os alunos construíram coletivamente um esquema de palavras soltas que representariam as suas concepções sobre Meio Ambiente naquele momento.

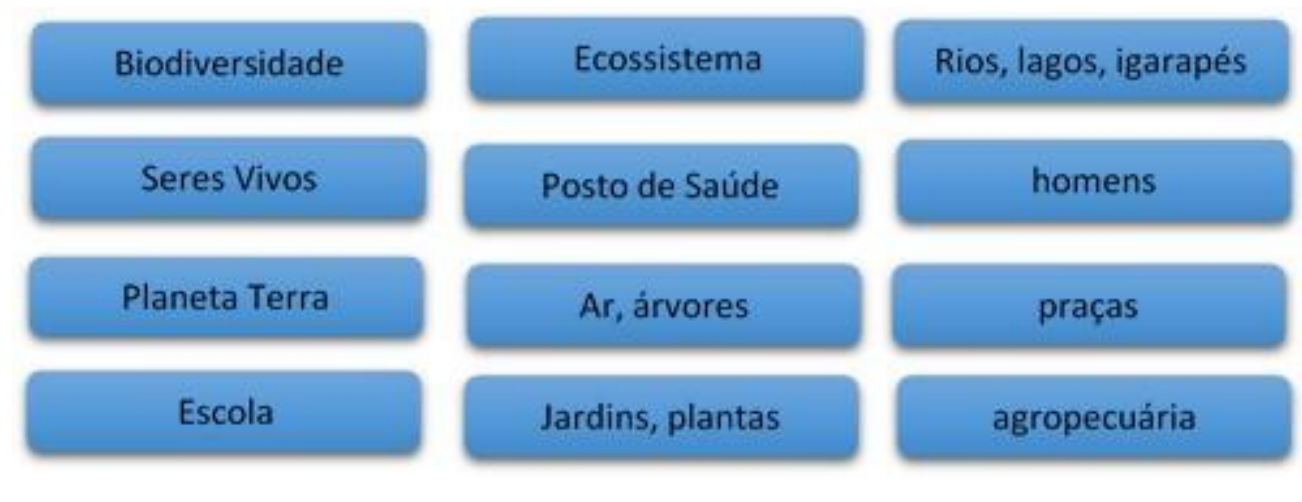

Quadro 1 - Mapa livre sobre as representações dos alunos sobre meio ambiente Fonte: Dados da Pesquisa

Nesse esquema, o homem já foi citado como aquele que faz parte do meio ambiente e conceitos como biodiversidade e agropecuária, mesmo ainda confusos quando os ouvimos pelos alunos começam a aparecer em suas falas. O ideal, nesse sentido, seria explorar esses temas, a fim de esclarecer os sentidos e conceitos aos alunos. 


\section{AULA-PASSEIO NO BOSQUE DA CIÊNCIA - INPA}

Todos ficaram muito motivados ao saberem que visitariam o bosque da ciência; a maioria iria pela primeira vez. O objetivo principal seria que essa aula passeio não fosse caracterizada com o perfil e forma de ensino comum, como a da sala de aula. Estimularíamos a dúvida, criatividade, incertezas e a problematização, o que possibilitaria uma leitura mais crítica sobre o meio ambiente.

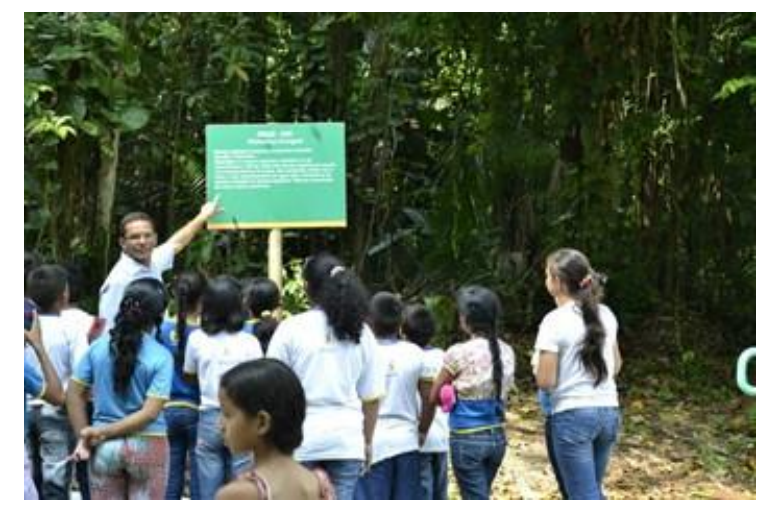

Figura 4 - Visita ao bosque da Ciência

Fonte: Dados da Pesquisa

As ariranhas são violentas? Quanto tempo elas vivem? Como vivem no cativeiro? E os peixes -boi, como se alimentam? São mansos? Por que possuem essa mancha branca no peito? De alunos encantados com os animais àqueles que construíram dúvidas sobre o modo de vida deles, estávamos frente a situações que possibilitaram um olhar naturalista, na medida que os alunos comentavam que gostavam dos animais, que cuidam e que precisamos preservar os animais, e de um pensamento crítico, quando questionavam o modo de vida deles em cativeiro. Mesmo quando orientados a visualizarem algumas situações como o histórico da árvore da Tanimbuca, o recanto dos Inajás, lago amazônico e a fauna livre, os alunos direcionavam-se àquilo que mais lhe interessavam, como os quelônios, macacos, o poraquê e os jacarés, além da expectativa de encontrarem alguma cobra no meio do caminho.

A casa da ciência foi o local onde eles passaram maior tempo observando e tirando fotos. Nesse local, podemos ver coleções de insetos, amostra de algumas espécies de peixes, anfíbios, frutos, sementes, casa do seringueiro, aspectos da história do Amazonas, dentre outras exposições. Os alunos, mesmo não podendo tocar na maioria das exposições, fitavam seus olhares no jacaré, cobra, arraia, borboletas, aranhas e nos aquários. A folha de dicotiledônea da Amazônia Ocidental, com 1,40m de largura e $2,50 \mathrm{~m}$ de comprimento também chamou bastante atenção dos alunos.

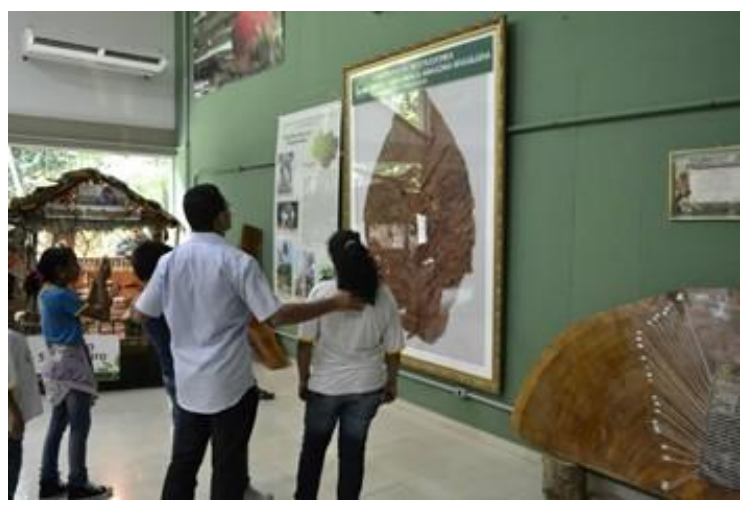

Figura 5 - Visita à casa da Ciência, no INPA

Fonte: Dados da Pesquisa 
Acredita-se que a visita ao bosque da ciência despertou a curiosidade e a dúvida. Todavia, é necessário estimular o pensamento crítico e problematizador. Ainda é muito forte e presente o pensamento de apenas amar, cuidar e preservar a natureza, o que não consideramos como problema, porém, é necessário iniciar um processo de reflexão crítica sobre as práticas ambientais, a fim de superar alguns obstáculos já que não são transpostos facilmente, mas ligados a resistências muito fortes (ASTOLFI, PETERFALVI e VÉRIN, 1998).

\section{A PREDOMINÂNCIA DO PENSAMENTO CONSERVACIONISTA}

Após os encontros realizados, verificamos que o lixo não era mais o principal aspecto citado quando falávamos de meio ambiente. Consideravam-se outros fatores e, em alguns casos, relações com o próprio homem. Trazemos comentários dos alunos, feitos por eles de forma escrita:

O Meio Ambiente não transmite só doenças, mas sim vida, alegria, felicidade e outros. É preciso conhecer direito o que está acontecendo com a Terra para que possamos ajudá-la com ações coletivas e coerentes (Aluno M).

A gente precisa do meio ambiente e o meio ambiente precisa de nós, então, por que cortar as árvores, arrancar as plantas, poluir os lagos, rios, mares, sujar as ruas, as calçadas, as praças. No passeio que teve na rua, eu observei muitas coisas, tipo a praça, ela faz parte do meio ambiente. Eu observei também os lixos que estavam acumulados em um canto. Eu acho que devia ter um esgoto ali (Aluno G).

O Meio Ambiente não é só de árvores e animais não, as casas e prédios e nós também fazemos parte dele. O ser humano tem construído muitos edifícios e não tem deixado espaço para as árvores e animais. Tudo tem que ser com ordem e decência. Vamos construir casas, mas também deixar espaços para os animais e as árvores porque nós também precisamos deles (Aluno D).

$\mathrm{O}$ relato do aluno $\mathrm{D}$ possui traços de um pensamento pragmático, de sustentabilidade, onde se pode utilizar o meio ambiente para a sobrevivência, mas com coerência, deixando em condições adequadas às gerações futuras. Os desenhos abaixo ratificam a predominância do pensamento conservacionista que inclusive é encontrado fortemente nos livros didáticos utilizados pelos alunos.

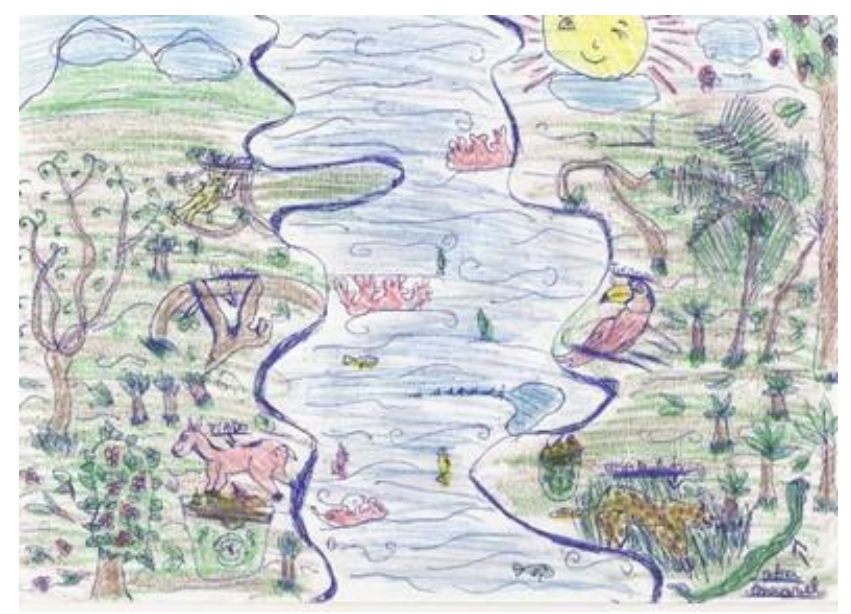

Figura 6 - Representações finais sobre meio ambiente

Fonte: Dados da Pesquisa

As concepções preservacionista e naturalista ficam bastante presentes nos desenhos acima e, apesar das tentativas de incorporar a tendência crítica, os alunos entendem meio ambiente e suas relações com a sociedade basicamente como ter amor, cuidar e preservar a natureza, em representações que em sua maioria reproduzem os instrumentos viabilizados pelo Estado e posteriormente, utilizados pela escola. 


\section{CONCLUSÕES}

Constatou-se que o conhecimento comum e imediato sobre meio ambiente que os alunos possuem, do tipo predominantemente conservacionista, torna-se um obstáculo muito resistente e que se constitui um obstáculo epistemológico ao conhecimento científico na área de educação ambiental. Mesmo com as orientações contidas nos PCN's e uma perspectiva de prática docente à luz da Ecopedagogia, há uma dificuldade tanto dos alunos quanto da escola em proporcionar momentos de reflexão sobre a relação de meio ambiente e sociedade.

Destaca-se que as representações dos alunos mudaram com o trabalho a partir da concepção de objetivos-obstáculos, mas que ainda foram tímidas e insuficientes para uma visão mais ampla sobre o meio ambiente. Todavia, reitera-se que esse é um caminho possível e significativo, uma vez que as representações iniciais dos alunos devem ser o ponto de partida para aquisição de novos conhecimentos. Ao longo dos encontros percebeu-se que os alunos sentiram-se participantes do processo de construção do conhecimento; traziam questionamentos porque consideravam que não eram erros, mas suas ideias, que naquele momento eram fortemente valorizadas e valiosas.

\section{REFERÊNCIAS}

ASTOLFI, J.P et all. As palavras-chave da didática das ciências. Lisboa: Instituto Piaget, 1997.

ASTOLFI, Jean-Pierre; PETERFALVI, Brigitte. VÉRIN, Anne. Como as crianças aprendem as ciências. Lisboa: Instituto Piaget, 1998.

AUSUBEL, D. P; NOVAK, J.D. \& HANESIAN, H. Psicologia educacional. 2 ed, Interamericana, RJ, 1980.

BACHELARD, Gaston.A formação do espírito científico: contribuição para uma psicanálise do conhecimento. Rio de Janeiro: Contraponto 1996.

BRASIL. Secretaria de Educação Fundamental. Parâmetros Curriculares Nacionais: meio ambiente e saúde. Brasília, 1997.

CARVALHO, Izabel Cristina de Moura. Educação Ambiental: a formação do sujeito ecológico. São Paulo: Cortez, 2008.

DUBET, François. O que é uma escola justa? a escola das oportunidades. São Paulo: Cortez, 2008.

FLECK, Ludwik. Gênese e desenvolvimento de um fato científico. Belo Horizonte: Fabrefactum, 2010.

FREINET, C. As técnicas Freinet da escola moderna. Lisboa: Estampa, 1975.

FRIGOTO, Gaudêncio. A produtividade da escola improdutiva. São Paulo: Cortez, 2006.

POZO, Juan Ignacio; CRESPO, Miguel Ángel Gómez. A aprendizagem e o ensino de ciências: do conhecimento cotidiano ao conhecimento científico. Porto Alegre: Artmed, 2009.

SANTOS, Maria Eduarda. Mudança conceptual na sala de aula: um desafio pedagógico. Lisboa: Livros Horizonte, 1991.

VASCONCELOS, Celso dos S. Desafio da Qualidade da Educação: Gestão da sala de aula. In: Gestão da Sala de aula. São Paulo: Liberta, 2014.Como as crianças aprendem as ciências. Lisboa: Instituto Piaget, 1998. 